rewritten or rearranged. The result is most successful and the author is to be congratulated on the considerable improvement achieved.

The chapters relating to radiotherapy, perhaps the most authoritative, now cover the more recent developments in high energy techniques. It is disappointing, however, that the chapter on radiodiagnostic procedures, while giving some space to recent developments in image intensifier and television techniques, has no mention of what is perhaps the most significant of recent advances, the application to this field of the principles of information theory. An elementary account of this, together with its implication of quantum limitations in the X-ray image, should surely have been included. In the chapter on the diagnostic use of artificial radioactive materials, the author has wisely elected to discuss a few established procedures rather than to eatalogue the many possible applications. Some reference might well have been included, however, to clinical uses of whole body counting; this technique receives only a brief mention in relation to personnel monitoring.

There is a carefully revised chapter on chemical and biological effects of ionizing radiations. From the student's point of view, the chapter on radiological protection would have benefited from more specific detail, for example on the methods of calibrating and interpreting film badges; and it might have been stressed that the data on maximum permissible burdens relate to maintained levels. The selection of examination questions and the references following each chapter have been brought as up to date as publishing time permits.

The book has commendable clarity and the care which seems to have been devoted to its style of expression makes such a lapse as "increasing quality" of radiation all the more remarkable. There is a tendency to overpunctuation, particularly in the insistence on a period after every unit abbreviation. Among errors and misprints noticed is the rather curious substitution of ytterbium for yttrium on page 166 and on page 466 it is implied that the $k$ factor is identical with the specific gamma ray constant, rather than a particular value of it. Presumably Fig. 11.43 reters to energy absorption in "average soft tissue elements" within bone, but the caption does not say so; in consequence a student might well be puzzled at the apparent discrepancy with Fig. 7.03. The text would have helped to avoid this confusion had it cross-referred to the earlier Section 11.14 on "dose absorbed in soft tissue elements in bone". Such oversights are considerably fewer than in the earlier edition, although the new book is more than half as long again.

This textbook can be warmly recommended to doctors preparing for their professional examinations in radiotherapy and radiodiagnosis and to new recruits in the field of medical physics.

G. W. REeD

\section{IONIZATION AGAINST MAN}

\section{Health Physics}

Principles of Radiation Protection. By D. J. Rees. Pp. $\mathrm{x}+242$. (London: Butterworth and Co. (Publishers), L.d., 1967.) $70 s$.

As increasing number of persons is now employed in duties concerned with protection against ionizing radiations. They range from graduates, mainly in physics and chemistry, to technicians or, indeed, industrial workers engaged in the day to day control of radioactive contamination and other aspects of radiation protection where considerable amounts of radioactive materials are manipulated. In addition, other groups of persons, such as teachers, administrators and public health officials, now require a knowreage of the principles of protection against ionizing radiations. There is thus an increasing need for education and training in the principles and tech- nology of health physics. It is also noteworthy that there is a conspicuous lack of appropriate textbooks in this field and the present volume is therefore very much to be welcomed.

This book is intended to provide a reasonable level of technical training for persons with no previous knowledge of the subject and with limited basic training in physics, chemistry, biology and mathematies. The book admirably achieves this objective and provides a clear and concise introduction to the subject. Starting with some basic physics such as the structure of matter, radioactivity and the interaction of ionizing radiations with matter, we are led on to a discussion of radiation dosimetry, the biological effects of radiation, standards of protection against radiation arising both internally and externally, the design of radioisotope laboratories and radiation protection measurements. There are many diagrams, some taken from specialized physics textbooks but others constructed especially by the author, and these contribute considerably to the value of the book in teaching and training.

Extensive reference is made to the recommendations of the International Commission on Radiological Protection, but it is unfortunate that the only reference to Publication 6 (1964) is in a postscript and no reference is made to Publication 9 (1966) which offers valuable flexibility in the method of compliance with the maximum permissible doses established by the Commission.

The chapter on biological effects of ionizing radiation provides an introduction to the structure of cells and cell division and devotes several pages to a discussion of the genetic effects of ionizing radiation. Somatic effects, however, are dealt with only briefly and attention is given mainly to the acute effects of whole body irradiation. The only reference to cancer is to induction of cancer of the skin after protracted exposures to high dose rates. There is no mention of the possible induction of cancer from significant amounts of radioactive nuclides lodged in the body, such as radium in the skeleton or radon decay products deposited in the lung, or of the induction of leukaemia from substantial whole body irradiation. The risks of the occurrence of these effects have been reviewed in a report of a Task Group to the International Commission on Radiological Protection, published in February 1966, and also in the reports of the United Nations Scientific Committee on the Effects of Atomic Radiation. Although the doses received, within the permissible limits for workers with ionizing radiations, are so low that the risk of these long-term effects is negligible, it is important that they should be recognized in any discussion of the biological effects of ionizing radiation.

The book contains a very extensive appendix on "Data useful for radiation protection problems". This is an admirable collection of data reproduced from a number of sources. This collection of information, however, is rather badly organized. There are examples of repetition of material; for example, beta particle ranges, beta absorption data, mass absorption coefficients, biological response and standards for radiochemical laboratories are each dealt with in more than one place, often with different figures, in the collected material, apparently as a result of quotation from a number of sourees. There is no list of contents to this part of the book. Moreover, many of the data do not quote the original source of publication. (This is partly the fault of the International Atomic Energy Agency, from which some of the data are derived.) The individual graphs and data, however, are useful and must be considered as part of the stock in trade of any operational health physicist. Despite its shortcomings, this is a valuable volume, providing an introduction to the subject and some measure of basic training in health physies as well as being a useful volume of reference for the practising health physicist.

W. G. MARLEY 